Article

\title{
Design and Experimental Verification of a 72/48 Switched Reluctance Motor for Low-Speed Direct-Drive Mining Applications
}

\author{
Esmail Elhomdy ${ }^{1,2}$, Guofeng $\mathrm{Li}^{1, *}$, Jiang Liu ${ }^{1}$, Syed abid Bukhari ${ }^{3}{ }^{(1)}$ and Wen-Ping Cao ${ }^{1,3}$ (1) \\ 1 School of Electrical Engineering, Dalian University of Technology, Dalian 116023, China; \\ esmail190@yahoo.com (E.E.); emu@mail.dlut.edu.cn (J.L.); w.p.cao@aston.ac.uk (W.-P.C.); \\ 2 Faculty of Engineering, Blue Nile University, Ad-Damazin 26613, Blue Nile State, Sudan; \\ eg_es.ali@hotmail.com \\ 3 School of Engineering and Applied Science, Aston University, Birmingham B4 7ET, UK; \\ bukhars2@aston.ac.uk \\ * Correspondence: guofenli@dlut.edu.cn; Tel.: +86-138-8962-6136
}

Received: 12 December 2017; Accepted: 10 January 2018; Published: 12 January 2018

\begin{abstract}
Typically, a geared drive system is used to connect an induction motor of $1500 \mathrm{rpm}$ with a Raymond Pulverizer of $105 \mathrm{rpm}$ in mining applications. This system suffers from low efficiency and a heavy motor drive. This paper proposes a novel design of a $75 \mathrm{~kW}, 72 / 48$ switched reluctance motor (SRM) for a low-speed direct-drive as for mining applications. The paper is focused on the design and comparative evaluation of the proposed machine in order to replace a geared drive system whilst providing a high torque low-speed and direct-drive solution. The machine performance is studied and the switching angle configuration of the machine is also optimised. The efficiency of the whole drive system is found to be as high as $90.19 \%$, whereas the geared induction motor drive provides only an efficiency of $59.32 \%$ under similar operating conditions. An SRM prototype was built and experimentally tested. Simulation and experimental results show that the drive system has better performance to substitute the induction motor option in mining applications.
\end{abstract}

Keywords: direct drive; geared motor drive; low speed; Raymond Pulveriser; switched reluctance motor; turn-on and turn-off angles

\section{Introduction}

Direct-drive motor systems are highly demanded in high-torque low-speed applications as they have high efficiency and high reliability. Induction motor (IM) drives mostly act as a driving force in industry and connect to the load through a mechanical reduction mechanism, such as a belt, a pulley or a gear. In general, IMs are not operated with low-speed and high torque in the absence of reduction mechanism [1]. The Raymond Pulverisers are widespread in the mining industry for speed in powder generation, and chemical processing is present by Raymond Pulveriser operated at a low-speed of $105 \mathrm{rpm}$, and requires a torque of $7 \mathrm{kN} \cdot \mathrm{m}$ [2]. Therefore, the motor drive should match this load profile via a gear mechanism for changing the rotating direction and keeping a constant torque at low speed as shown in Figure 1. The features of a conventional IM drive used in the Raymond Pulveriser are given in Table 1 [3]. 


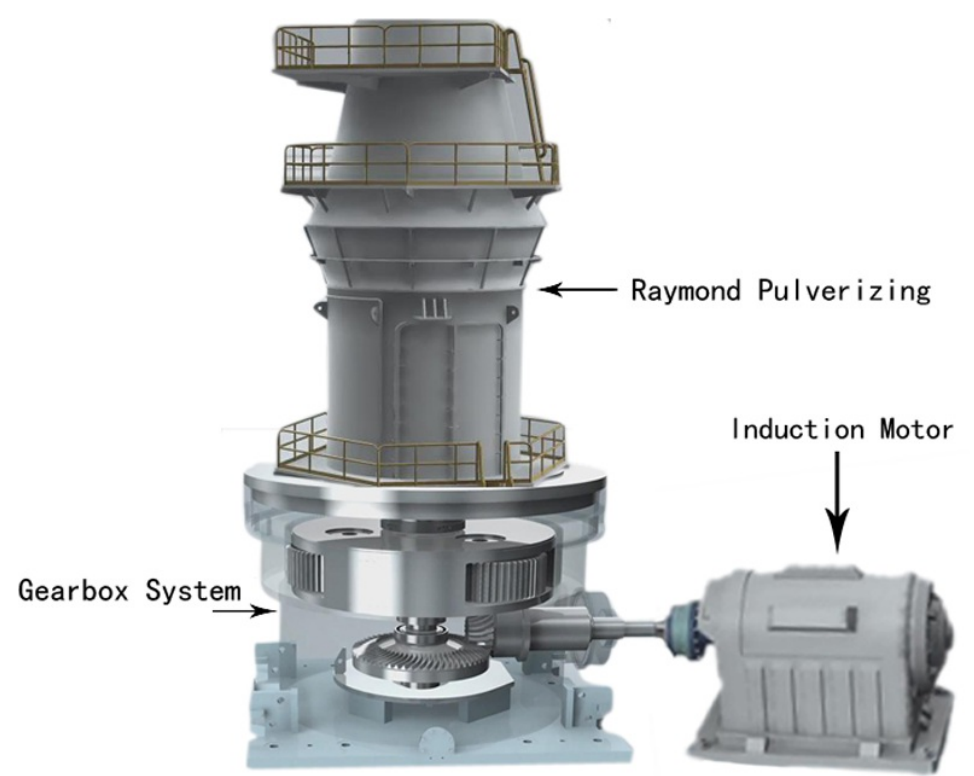

Figure 1. The existing gear drive system used in Raymond Pulverizing.

Table 1. The features of conventional induction motor drive in the Raymond Pulveriser.

\begin{tabular}{lclc}
\hline Parameter & Value & Parameter & Value \\
\hline Power [kW] & 75 & Weight [Kg] & 678 \\
Voltage [V] & 400 & The gear system outer diameter [mm] & 1000 \\
Current [A] & 128 & The gear system stack length [mm] & 340 \\
Frequency [Hz] & 50 & The output speed of a gear system [rpm] & 105 \\
Power factor at full load & 0.9 & The efficiency of a gear system [\%] & 62.98 \\
Rate Speed [rpm] & 1488 & The total weight of a gear drive system [kg] & 1050 \\
Rate torque [N·m] & 481 & The total efficiency of a gear drive system [\%] & 59.32 \\
Efficiency at full load [\%] & 94.2 & & \\
\hline
\end{tabular}

The total efficiency of the conventional drive system is $59.32 \%$, resulting from multiplying the efficiency of the gear system (62.98\%) and the motor (94.2\%). The drive mechanism of a Raymond Pulveriser can be classified as geared drive and direct-drive, as shown in Table 2 (see [4-6]). The gear drive system has been the mechanism used widely; the motor output torque is conveyed by a gear. However, the gear drive system has some drawbacks such as low efficiency, high noise, and vibration created by the mechanical decline mechanism [7]. On the contrary, a direct-drive system has a preference for high reliability and high dynamic accuracy, thus eliminating the problems associated with the gear mechanism [7-10]. Direct-drive motors are generally employed in servo applications where high performance is expected. The development of a low-speed direct-drive for the wet grinding application by using an External-Rotor Synchronous Reluctance Motor was presented [11]. A direct-drive robot consisting of a mechanical arm of electrical motors directly coupled to the joints was described [12].

As the industrial standards continue to improve, high-efficiency motor drives are gaining popularity in mining industry. As a first step, direct-drive systems can eliminate some troublesome mechanical components so as to improve the energy efficiency, as well as noise, vibration and maintenance. As previously mentioned, the conventional drive system used in Raymond Pulverizing provides only an efficiency of $59.32 \%$; this is very low efficiency. Moreover, the drives used conventionally for this type of application can not start up to full load. As energy savers, high efficiency is becoming very significant, as low noise and vibration. As a result, direct-drive motors systems have become attractive for Raymond Pulverizing appliances. The proposed motor works on the principle of direct-drive Raymond Pulverizing, which is indicated in Figure 2. 
Table 2. The drive mechanism of the Raymond Pulveriser.

\begin{tabular}{|c|c|c|c|}
\hline Construction & Geared Drive System & \multicolumn{2}{|c|}{ Direct-Drive System } \\
\hline Gear Ratio & About 14.28:1 & \multicolumn{2}{|l|}{ - } \\
\hline Balance & Poor & \multicolumn{2}{|l|}{ Good } \\
\hline Noise & High & \multicolumn{2}{|l|}{ Low } \\
\hline Efficiency & Low & \multicolumn{2}{|l|}{ High } \\
\hline Reliability & Moderate & \multicolumn{2}{|l|}{ High } \\
\hline Lubrication System & Significant & \multirow{2}{*}{\multicolumn{2}{|c|}{$\begin{array}{l}\text { No Significant } \\
\text { Short time }\end{array}$}} \\
\hline Maintainability & Longer time & & Short time \\
\hline Motor & Induction Motor & Brushless DC & Switched Reluctance Motor \\
\hline Torque & Small & Larger & Larger \\
\hline Cost & Cheap & Expensive & Cheaper \\
\hline Weight & Medium & Medium & Larger \\
\hline Limiting thermal & Winding insulation & Winding insulation andpermanent magnet & Winding insulation \\
\hline Coolant system & Stator and rotor & Stator and Rotor & Stator (Only) \\
\hline
\end{tabular}

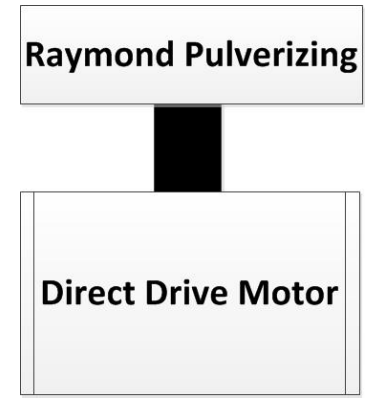

Figure 2. Proposed motor founded direct-drive Raymond Pulverizing.

As the industrial standards continue to improve, high-efficiency motor drives are gaining popularity in the mining industry. As a first step, direct-drive systems can eliminate some troublesome mechanical components so as to improve the energy efficiency, as well as noise, vibration and maintenance. In industry, the widely used motors for such applications are induction motors, and permanent magnet synchronous motors (PMSMs). However, they both have their advantages and drawbacks [7]. Switched reluctance machines (SRMs), as an alternative, have features such as high torque at low speed, cheapness and reliability. These make them attractive in safety-critical applications $[13,14]$. SRMs have the potential to replace induction motors in Raymond Pulveriser applications, as they can work at higher temperatures and increased robustness [13-17]. As SRMs do not use PMs on their rotor, the cost of these motors is significantly lower $[15,16]$. This work is focused on developing high torque motor drive systems for environmentally hazardous mining applications based on the finite element method. Extensive work has been done on the machine performance analysis under various operating conditions.

\section{Design of a Switched Reluctance Motor}

In order to develop design, the geometrical configuration of the motor, phase number, stator and rotor tooth numbers, and winding are considered. Unlike conventional AC and DC motors, SRMs work under a different torque output principle. Torque production in an switched reluctance motor is based on an energy conversion process. When one phase of the motor is excited, the energy from the power input is transferred to the phase winding. Part of the energy, which is also known as the co-energy, is utilized to produce the mechanical power in the rotor and rotating part to shift to a state of maximum inductance, which coincides with the position of minimum reluctance [18-21]. For a motor that rotates at constant speed with voltage supplied to the position whose phase is not aligned, the equation of voltage is given by 


$$
V_{s}=R i+L \frac{\mathrm{d} i}{\mathrm{~d} t}+i \omega_{m} \frac{\mathrm{d} L}{\mathrm{~d} \theta}
$$

where $V_{s}$ is the supply voltage, $\theta$ is the rotor position and $\omega_{m}$ is the angular speed. $i, L$ and $R$ are the current, inductance and resistance of the phase, respectively. Prior to reaching saturation, the instantaneous electromagnetic torque can be simplified to [18]

$$
T_{e}=\frac{1}{2} i^{2} \frac{\mathrm{d} L}{\mathrm{~d} \theta}
$$

However, the instantaneous torque is not necessarily constant. Torque of the SRM is related to the difference of the inductances. The computation of the average torque is based on the number of energy conversion loops per revolution. That is, the number of strokes per revolution, the average torque over a revolution is specified by [18-21]:

$$
T_{a v}=\frac{S W}{2 \pi} .
$$

The co-energy is represented by $W$, which is an area between the fully aligned rotor position to the fully unaligned rotor position, one in the conversion loops' profile of the energy. The number of rotor poles $P_{r}$ and the phase numbers $q$ can be related to the stroke numbers per revolution $S$, as follows [18-20]:

$$
\begin{gathered}
S=q P_{r}, \\
q=\frac{P_{s}}{\left|P_{s}-P_{r}\right|},
\end{gathered}
$$

where $P_{S}$ is the number of stator poles. Then, the stroke angle is the minimum conduction angle, which is given as follows:

$$
\epsilon=\frac{2 \pi}{q P_{r}} .
$$

Generally, torque ripple and an average of the torque can be calculated from Equations (7) and (8). In addition, the difference between the maximum and minimum torque as the ratio of the average torque is defined as torque ripple:

$$
\begin{gathered}
T_{a v}=\frac{W P_{s} P_{r}}{2 \pi\left|P_{s}-P_{r}\right|}, \\
T_{\text {ripple }}=\frac{T_{\max }-T_{\min }}{T_{a v}} \times 100 \% .
\end{gathered}
$$

The passing frequency of the rotor pole is equal to the fundamental frequency of the current in each phase, which is given by

$$
f_{1}=\frac{N_{r} P_{r}}{60}
$$

$N_{r}$ is the rotor speed [rpm].

SRM has numerous combinations of the stator and the rotor poles number. Therefore, the advantages and drawbacks have been scouting in detail [18-20]. For SRM, the relation between the pair number of magnetic pole $p$, numbers of the poles and number of electrical phases $q$ can be expressed as [22]:

$$
\left.\begin{array}{l}
P_{s}=2 p q, \\
P_{r}=2 p(q-1) \quad \text { if } \quad P_{r}<P_{s} \\
P_{r}=2 p(q+1) \quad \text { if } \quad P_{r}>P_{s} .
\end{array}\right\}
$$

An advantage of the machines having a larger pole number is a smaller stroke angle, leading to a high average torque, a lower torque ripple and shorter end-windings [16,23]. However, the core loss can be higher, with the increased frequency. Therefore, a three-phase 72/48 SRM with the topology 
is proposed in this paper. This is based on a 6/4 SRM configuration with the multiplication of 12; the winding coils around twenty-four stator poles form a phase. The inductance duty cycle of the stator and the rotor is $90^{\circ}$ and $7.5^{\circ}$, respectively. The angular rate of inductance changes for the $72 / 48$ SRM is twelve times of a $6 / 4$ equivalent. This configuration has short end-windings and short flux paths minimizing the copper loss as well as acoustic noise [18-21]. 72/48 SRM is possibly the widespread configuration for three-phase machines in a mining application. In this design, the generated torque is greater than $7 \mathrm{kN} \cdot \mathrm{m}$ and the rated machine speed is $105 \mathrm{rpm}$ as shown in Table 1.

The empirical formula as obtained from the previous technical literature, as well as designed experience, resulted in the design process [13-16]. Two approaches can be used: the first one is presented in [15] while another one is proposed by $[16,17]$. Regarding the similar method of calculation for these two approaches, both of these are based on the output equations that are given here:

$$
\begin{gathered}
T=k D_{r}^{2} L_{s t k}, \\
P_{d}=\frac{\pi^{2}}{120} k_{d} k_{2} A_{s} B D_{r}^{2} L_{s t k} N_{r} \eta,
\end{gathered}
$$

where $T$ is the torque and $P_{d}$ is the power developed, $K$ is coefficient of the output, $k_{d}$ is the duty cycle, and $\eta$ is the efficiency. $A_{s}$ and $B$ are the specific electric and magnetic loading. $k_{2}$ is a variable dependent on the operation point of the motor [15-17]. For defining prime dimensions, the length of stack $L_{s t k}$ should be multi-, or submultiple of a parameter called bore diameter $D_{r}$ [13].

This work provides a detailed description of the proposed design of switched reluctance motor low speed direct drive (SRMLSDD). The goal of the design was to analyze and modify the motor geometry to improve average torque, maximum efficiency and trying to reduce torque ripple. In two steps, the design method, step 1 , is the general size equation for 72/48 SRM. Then, the initial design parameters of the specified 72/48 SRM have been decided. Step 2 includes optimization of the parameters such as the back irons, arcs of pole and heights of the pole on the performance of $72 / 48$ SRM. Moreover, the geometrical dimensions of the final design for the specified SRMLSDD are obtained.

\subsection{Step 1 Initial Design}

The design of SRMLSDD has the same volume of the gear system employed in Raymond Pulverizing. Therefore, the stator outer diameter and a stack length of the SRMLSDD are set as $1000 \mathrm{~mm}$ and $340 \mathrm{~mm}$, respectively (see Table 1). The discussion of more choices of design will be carried out in this part such as outer rotor diameter, the thickness of the yoke, air gap, pole arcs, and heights of the pole for example, Equation (11), in order to determine the rotor out diameter $D_{r}$, specifically the stake length $340 \mathrm{~mm}$ and the output torque $7 \mathrm{kN} \cdot \mathrm{m}$. In this paper, $k=32.33 \mathrm{kN} \cdot \mathrm{m}^{-2}$ is mentioned, which is a specific value of high performance industrial with liquid cooling [19]. However, the rotor diameter can be obtained from Equation (11) as $D_{r}=798 \mathrm{~mm}$. For subsequent determining of the configuration and the outer dimensions of the SRMLSDD, we need to pay attention to it is internal dimensions. The torque and power density of the motor are affected by the length of the air gap. The tolerance of the manufacturing is dependent on this parameter. Therefore, the air gap is adopted $g=1 \mathrm{~mm}$. The pole arcs $\beta_{s}$ and $\beta_{r}$ selection have some limitations [16] as follows:

$$
\left.\begin{array}{l}
\beta_{r} \geq \beta_{s}, \\
\min \left(\beta_{s}, \beta_{r}\right) \geq \frac{2 \pi}{q P_{r}}, \\
\beta_{s}+\beta_{r}<\frac{2 \pi}{P_{r}},
\end{array}\right\} .
$$

In this paper, $\beta_{s}=2.95^{\circ}$ and $\beta_{r}=3.05^{\circ}$ are selected to satisfy the constraints on Equation (13). Therefore, Equations (14) and (15) give rise to the pole width of the rotor and stator given by $[15,16]$

$$
t_{s}=\left(D_{r}+2 g\right) \sin \left(0.5 \beta_{s}\right)
$$




$$
t_{r}=D_{r} \sin \left(0.5 \beta_{r}\right) .
$$

The results are $t_{s}=20.59 \mathrm{~mm}$ and $t_{r}=21.23 \mathrm{~mm}$. Reducing acoustic noise is achieved by minimization of the additional factors of vibration and maximum flux density; this factor is determined by the stator yoke thickness $b_{s y}[13,16]$. The SRM's first mode frequency can regulate the vibration and acoustic noise. It is dependent on $b_{s y}$ as described by [13]

$$
w_{f m}^{2}=\frac{E b_{s y}^{2}}{6 \rho\left(1-\gamma^{2}\right)\left(\frac{\pi^{2}}{4}-2\right)\left(\frac{D_{0}-b_{s y}}{2}\right)^{4}} .
$$

$D_{o}$ is the outer diameter of the stator lamination stack, $E$ is the modulus of elasticity, $\gamma$ is the Poisson ratio, and $\rho$ is the mass density of the lamination material. Therefore, higher thickness $b_{s y}$ is advantageous and it increases the first mode frequency and gives higher mechanical strength, both of which are beneficial to reduce acoustic noise and vibration. It could have a value of the range satisfying the minimize vibration and robust mechanics:

$$
t_{s}>b_{s y} \geq 0.5 t_{s}
$$

Thereby, it is advised to choose a value that is higher than $b_{s y}$ [13]. The $b_{s y}$ can be achieved by:

$$
b_{s y}=0.75 t_{s}=15.45 \mathrm{~mm} .
$$

It is necessary that the stator slot depth $h_{s}$ should be large enough to increase the winding area but decreases the copper loss $h_{s}$, which is determined by:

$$
h_{s}=0.5\left(D_{s}-D_{r}-2\left(g+b_{s y}\right)\right)=84.55 \mathrm{~mm} .
$$

The mechanical integrity of the rotor and the operating flux density depend on the rotor yoke thickness $b_{r y}$. For rotor flux saturation, $b_{r y}$ should be within a range:

$$
0.5 t_{r} \leq b_{r y}<0.75 t_{r}
$$

In this paper, the $b_{r y}$ is chosen as:

$$
b_{r y}=0.74 t_{r}=15.71 \mathrm{~mm} .
$$

For achieving low inductance at the totally unaligned, the rotor slot depth $h_{r}$ must be 20 to 30 times of the length of the air gap [13]:

$$
h_{r}=k_{h r} g, \quad \text { where } 20<k_{h r}<30 .
$$

Here, the $h_{r}$ is chosen as:

$$
h_{r}=29 g=29 \mathrm{~mm} \text {. }
$$

For holding the rotor's lateral stiffness, the shaft diameter $D_{s h}$ should have a maximum length. It can minimize acoustic noise as the first critical speed increases $[13,18] . D_{s h}$ is hereby determined from the rotor dimensions discussed above

$$
D_{s h}=D_{r}-2\left(h_{r}+b_{r y}\right)=708.58 \mathrm{~mm} .
$$

The winding's number of turns considerably affects the performance of the machine. The fact that it is given by this calculation is very significant, created on the basic of the phase-winding voltage calculation. The number of turns around each stator pole $N_{p}$ is given by $[15,17]$ 


$$
N_{p}=\frac{\pi V_{s}}{w_{m} t_{s} L_{s t k} B_{s} q P_{r}} .
$$

The converter is powered by a $510-\mathrm{Vdc}$ power supply. The $B_{s}$ is the saturation flux, which is selected as $1.7 \mathrm{~T}$ for ferromagnetic material M19-29gauge. Then, from Equation (22), the $N_{p}$ of the proposed SRM design are obtained as 12 turns.

The slot fill factor $F_{\text {slot }}$ indicates the ratio of the total cross-section area of the conductors to the total slot area, which includes the slot liners, slot separators, conductors, and insulations. The $A_{S}$ is defined as the linear current density around the air gap circumference, as the $A_{s}$ is restricted by $F_{\text {slot }}$ and $h_{s}$. The relationship of $A_{s}$ and the current density $J$ is given by [19]:

$$
J=\frac{A_{s}}{h_{s}(1-\tau) F_{\text {slot }}}
$$

where $\tau$ the ratio of the tooth width to the slot-pitch. The initial design parameters of the proposed $72 / 48$ SRM have been decided and are hereby given in Table 3.

Table 3. The initial design parameters of the specified 72/48 SRM.

\begin{tabular}{lclc}
\hline Parameter & Value & Parameter & Value \\
\hline Number of stator poles & 72 & Stack length [mm] & 340 \\
Number of rotor poles & 48 & Air gap length [mm] & 1 \\
Stator out diameter [mm] & 1000 & Rotor out diameter [mm] & 798 \\
Stator pole arc angle [deg] & 2.95 & Rotor pole arc angle [deg] & 3.05 \\
Stator pole width [mm] & 20.59 & Rotor pole width [mm] & 21.23 \\
Stator yoke thickness [mm] & 15.45 & Rotor yoke thickness [mm] & 15.71 \\
Stator slot depth [mm] & 84.55 & Rotor slot depth [mm] & 29 \\
Number of turns per pole [Turns] & 12 & Shaft diameter [mm] & 708.58 \\
Number of coils per slot & 2 & Slot fill factor [\%] & 56.3 \\
\hline
\end{tabular}

\subsection{Step 2 Optimization of the Parameters}

The next major parameters such as $\beta_{s}, \beta_{r}, b_{s y}, b_{r y}, N_{p}$ and $D_{s h}$ are optimized against the machine performance whilst fixing the stator and rotor outer dimensions, stack lengths, and the air gap. Furthermore, this paper proposes design methodology to increase the average of the torque $T_{a v}$ and reduce torque ripple $T_{\text {ripple }}$. At first, we check which parameters influence the $T_{a v}$ and $T_{\text {ripple }}$. Figure 3 shows the average torque, and torque ripple profile characteristics with parameters independently change, where only one parameter is changed and other parameters are kept constant with a fixed control strategy, as shown in Figure 3. The values of the control strategy are input voltage $510 \mathrm{~V}$ and hysteresis control central current $700 \mathrm{~A}$. The current is controlled by hysteresis current control in order to be kept around a central value of $700 \mathrm{~A}$. The influence of the major parameters on the motor is given by [20]:

$$
\begin{gathered}
T(i, \theta)=\left.\frac{\partial W}{\partial \theta}\right|_{i=\text { constant }}, \\
W(i, \theta)=\int_{0}^{i} \psi d i,
\end{gathered}
$$

where $T, W, \psi$, and $\theta$ are the torque, co-energy, flux linkage and rotor position, respectively. The package of SPEED inclusive of the PC-based switched reluctance drive analysis (PC-SRM) and a finite-element analysis (PC-FEA) are utilized to carry out optimization processes for $72 / 48$ SRM. As shown in Figure 3, parameters such as $\beta_{s}, \beta_{r}, b_{s y}, b_{r y}, N_{p}$, and $D_{s h}$ have the significant impact for the $T_{a v}$ and $T_{\text {ripple }}$. These parameters are relevant to magnetic resistance and have a lot of impact on $\psi-i$ characteristics. Figure 3a shows the investigation of the influence of the stator pole arc angle on the average torque, and torque ripple, for stator pole arc angle in the range $\left(2.7^{\circ}\right.$ to $\left.3^{\circ}\right)$. Similarly, Figure $3 \mathrm{~b}-\mathrm{d}$ show the variations in the average torque, and torque ripple, in the rotor pole 
arc angle in the range $\left(2.95^{\circ}\right.$ to $\left.3.2^{\circ}\right)$ and present effects of stator yoke thickness (10 to $\left.30 \mathrm{~mm}\right)$ and rotor yoke thickness ( 15 to $25 \mathrm{~mm}$ ) on the average torque and torque ripple. Simulations were run by changing the number of turns between (three to seven turns). Figure 3e shows that the highest average torque may be obtained with 15 turns per coil. Below this value, the torque is lower due to the fact that the magnetomotive force is lower for the lower number of turns and the same current. For higher number of turns, the average torque is limited by two phenomena: the time for the current to rise up to peak value and the back electromotive force. These two limitations reduce the root mean square value of the current, and are more pronounced with a high number of turns. Figure $3 \mathrm{f}$ shows that the shaft diameter has a considerable effect on torque ripple and torque. However, in practice, $D_{s h}$ cannot be optimized based on this result because the shaft diameter should be a certain value from the point of reducing noise and vibration. The mechanical limitation of the shaft diameter can be calculated by using Equations (16) and (26). The minimum diameter of the shaft $D_{s h_{\min }}$ can be calculated as

$$
D_{s h_{\min }}=1.72\left(\frac{T_{\max }}{\tau_{\max }}\right)^{\frac{1}{3}},
$$

where $\tau_{\max }$ and $T_{\max }$ are the maximum of the shear stress and torque, respectively.

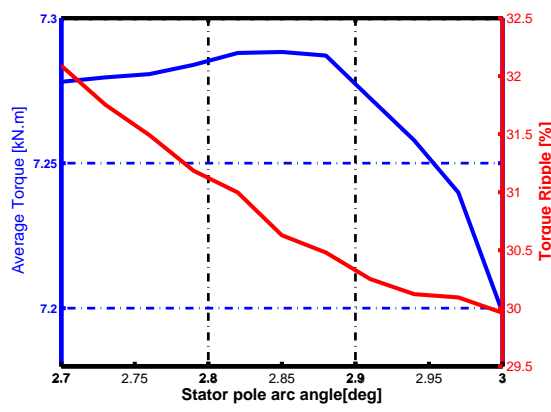

(a)

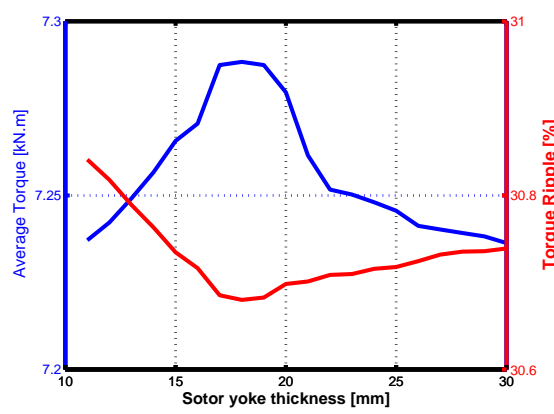

(c)

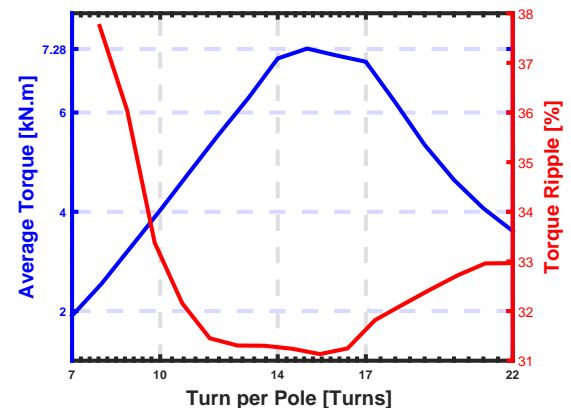

(e)

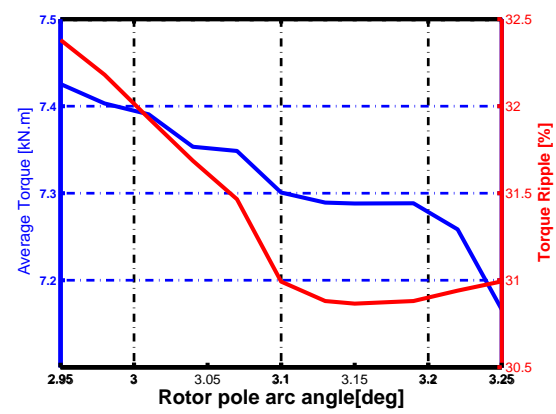

(b)

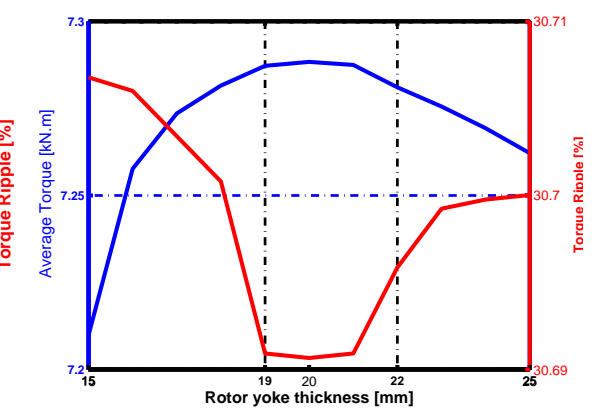

(d)

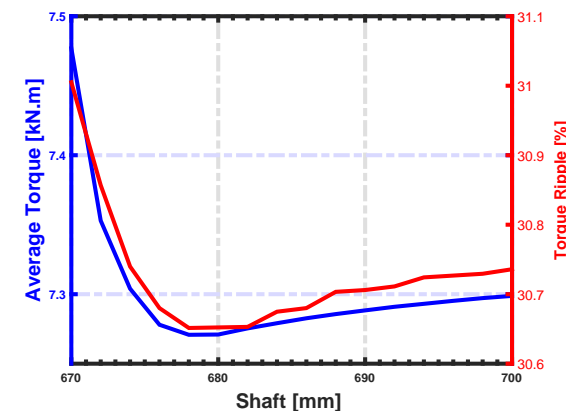

(f)

Figure 3. Variations of the torque and torque ripple when parameters changed independently. (a) $\beta_{s}$; (b) $\beta_{r} ;$ (c) $b_{s y} ;$ (d) $b_{r y} ;(\mathbf{e}) N_{p} ;(\mathbf{f}) D_{s h}$. 
Standard optimization is done by the method in which each parameter changed one by one. However, changing parameters simultaneously is an ideal optimization, when analysis time is acceptable. As a compromise, preferential parameters such as $\beta_{s}, \beta_{r}, b_{s y}, b_{r y}$, and $N_{p}$, are changed simultaneously. The torque ripple and torque profile when changing the preference parameters simultaneously are displayed in Figure 4. The optimal values of the preferential parameters are $\beta_{s}=2.85^{\circ}, \beta_{r}=3.15^{\circ}, b_{s y}=18 \mathrm{~mm}, b_{r y}=20 \mathrm{~mm}$, and $N_{p}=15$ Turns. Then, the other parameters are obtained through Equations (14) to (20), respectively. The geometrical dimensions of the final design of the specified $72 / 48$ SRM are detailed in Table 4.

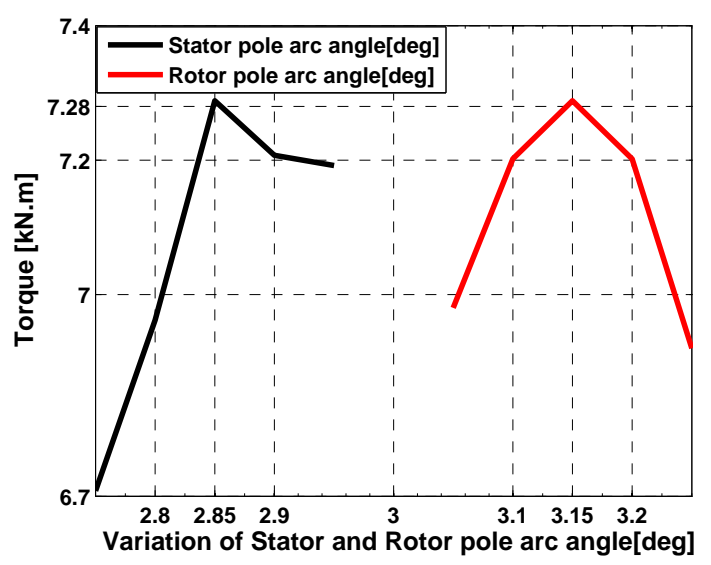

(a)

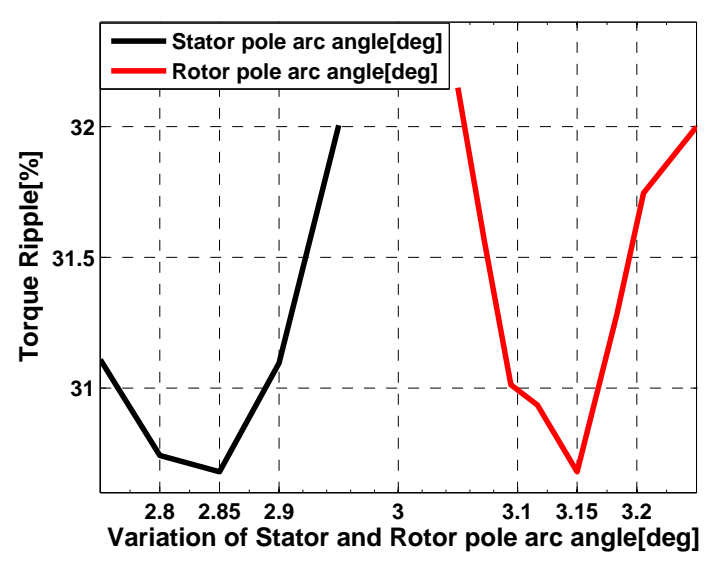

(c)

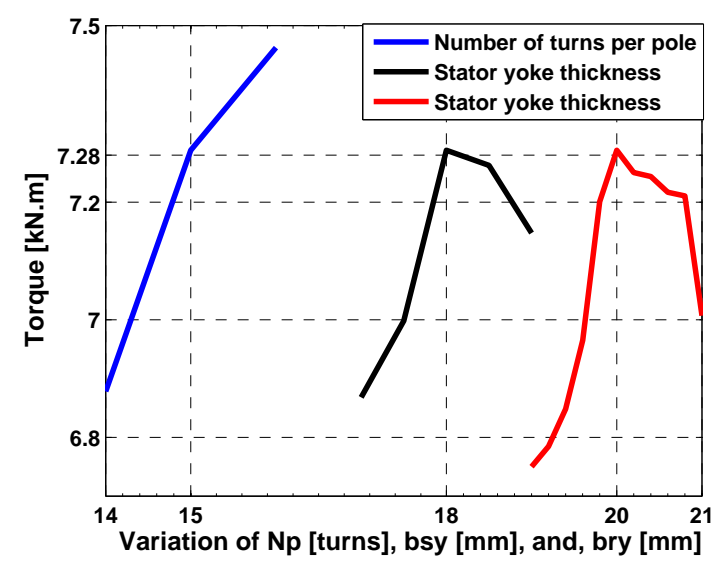

(b)

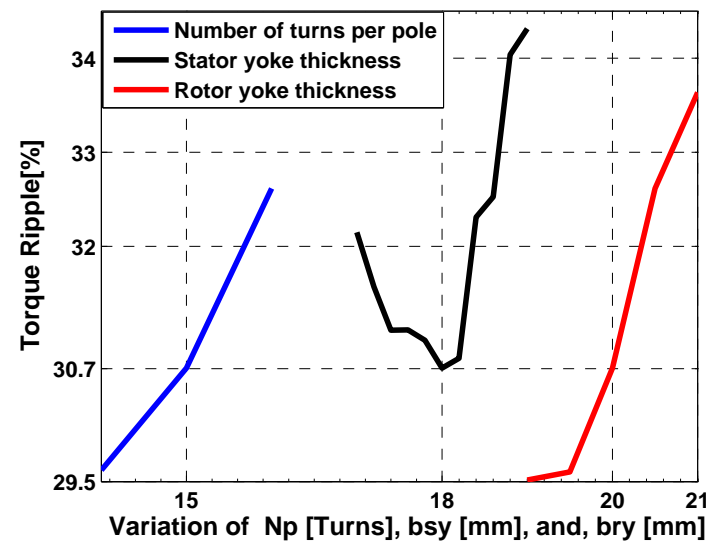

(d)

Figure 4. Variations of the torque and torque ripple when changing the preference parameters simultaneously. (a) $\beta_{s}$ and $\beta_{r} ;(\mathbf{b}) b_{s y}, b_{r y}$ and $N_{p} ;$ (c) $\beta_{s}$ and $\beta_{r} ;(\mathbf{d}) b_{s y}, b_{r y}$ and $N_{p}$.

Table 4. The geometrical dimensions of the final design of the specified 72/48 SRM.

\begin{tabular}{lclc}
\hline Parameter & Value & Parameter & Value \\
\hline Number of stator poles & 72 & Stack length [mm] & 340 \\
Number of rotor poles & 48 & Air gap length [mm] & 1 \\
Stator out diameter [mm] & 1000 & Rotor out diameter [mm] & 798 \\
Stator pole arc angle [deg] & 2.85 & Rotor pole arc angle [deg] & 3.15 \\
Stator pole width [mm] & 19.89 & Rotor pole width [mm] & 21.93 \\
Stator yoke thickness [mm] & 18 & Rotor yoke thickness [mm] & 20 \\
Stator slot depth [mm] & 82 & Rotor slot depth [mm] & 39 \\
Number of turns per pole [Turns] & 15 & Shaft diameter [mm] & 680 \\
Number of coils per slot & 2 & Slot fill factor [\%] & 70.3 \\
\hline
\end{tabular}


The arc angle of the stator pole is lower compared to the initial model. Therefore, the optimum design has greater $N_{p}$, thus increasing the $F_{\text {slot }}$. Increasing the $F_{\text {slot }}$ of the windings is one of the solutions to decreasing the losses, which also enhances the heat transfer performance [24]. Figure 5 displays an evaluation of the energy loop profile (flux-linkage vs. current) of the initial and optimized design. The rate of change inductance of optimization design near unaligned position goes fast as compared to the initial design; as a result, the torque of the initial is low in this region. The inductance stays almost constant at the fully overlapping of stator and rotor poles. It is clear that the area of the energy conversion loop of optimization designed is larger than the initial design. Therefore, the final design will be given a higher torque up to $7 \mathrm{kN} \cdot \mathrm{m}$ and lower torque ripple. Meanwhile, the diagram of optimization design of the prototype 72/48 SRM is presented in Figure 6.

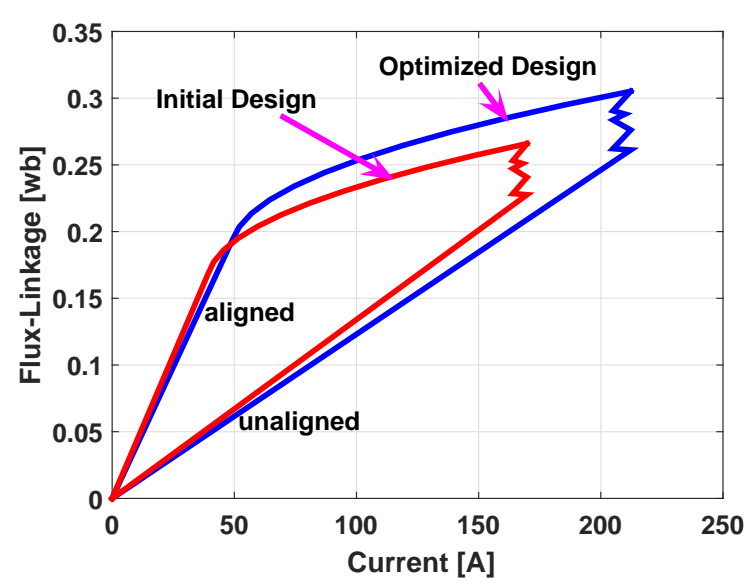

Figure 5. Comparison of the energy conversion loop $\psi-i$ characteristics' curves in two designs.

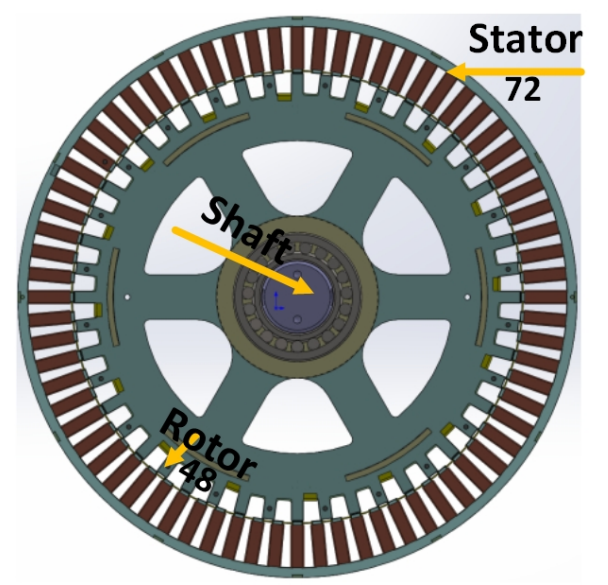

Figure 6. The construction of prototype $72 / 48$ SRM.

\section{Investigation of Losses}

The losses in electrical machines can be classified by the spatial distribution of heat sources. The calculations of copper, core, and mechanical loss are specific in the subsequent parts.

\subsection{Stator Copper Loss}

For non-overlapping currents, the current waveform of each phase is a rectangular wave, and the total copper loss in the stator is given as [13]:

$$
P_{c u}=R_{s} I_{p}^{2}
$$


where $I_{p}$ is the peak value of the phase current and $R_{s}$ is the resistance per phase. For the overlapping currents in the stator, the total copper loss is obtained as:

$$
P_{c u}=R_{s}\left(1+\frac{T_{r}+T_{f}}{3 T_{p c}}\right) I_{p}^{2}
$$

where $T_{r}$ and $T_{f}$ are the rise and fall times of the current, respectively. The duration of the varying stage inductance is given by:

$$
T_{p c}=\frac{2 \pi}{\left(q P_{r} \omega_{m}\right)}
$$

The time duration of varying phase inductance depends on the speed. Similarly, the copper loss is also determined by the speed.

\subsection{Core Loss}

The core loss forecast is a significant part of the design strategy of the machine. In the SRM, core loss is difficult to predict because of the change in flux densities caused by the different frequencies in the stator segments. In addition, this loss depends on the form of the current waveforms in the different portions of the magnetic circuit. Therefore, a proper appreciation of the core loss in SRM would require frequency and flux density decomposition in each portion [13-15]. The core loss in an SRM encompasses hysteresis, eddy current, and excess loss. Thus, the core loss is obtained using the Bertotti modified equation as [25-27]:

$$
P_{\text {core }}=k_{n} f B^{a+b B}+k_{e} f^{2} B^{2}+k_{e x} f^{1.5} B^{1.5} .
$$

The parameters $a$ and $b$ are the constant, $B$ is flux density, and $f$ is the frequency, while: $k_{n}, k_{e}$, and $k_{e x}$ are, respectively, hysteresis, eddy current, and excess coefficients.

\subsection{Mechanical Loss}

The loss $P_{\text {mec }}$ represents energy lost in bearing friction and rotating parts. Mechanical loss $P_{\text {mec }}$ depends on the properties of the lubricant, type of bearing, the load on bearing and the shaft speed. Moreover, it consists of the windage losses $P_{\text {wind }}$ due to the rotation of the moving machine portion in the air gap, and the bearing friction losses $P_{b f r}$ in bearings on the motor rotation:

$$
P_{\text {mech }}=P_{b f r}+P_{\text {wind }} \text {. }
$$

There are many empirical equations that have determined the mechanical losses giving various degrees of accuracy $[25,28-30]$. The bearing friction and windage losses of $72 / 48$ SRM can be calculated as:

$$
P_{f r}=\frac{\pi}{4} \rho k_{f b} N_{r} D_{r}^{2} L_{s t k} 10^{-3} .
$$

$\mu_{f r}$ is friction coefficient, $F_{b r}$ and $D_{b r}$ are bearing load, the inner diameter of the bearing [28,30]:

$$
P_{\text {wind }}=\frac{1}{32} \pi \rho \omega_{m}^{3} k_{r g} C_{M} L_{s t k} D_{r}^{4}+\frac{1}{64} \rho \omega_{m}^{3} C_{M}\left(D_{r}^{5}-D_{s h}^{5}\right) .
$$

$k_{r g}$ is a roughness coefficient, $C_{M}$ is the torque coefficient and $\rho$ is the density of the coolant. Equation (33) shows that the windage losses are divided into two parts of the losses such as in the air gap and the end surfaces of the rotor. The torque coefficient $C_{M}$ depends on the Couette Reynolds number. It is specified by measurements [28]. 


\section{Converter Topology and Optimization Turn-on and Turn-off Angle}

The power converter is a power source unit that realizes the order for the controller to energize each phase of the motor at proper times. Based on the application, the choice of converter topology is a significant issue. The SRM converter has certain requirements, which are given in [31,32]. The optimum behavior of the SRM based on the convenient situation of the currents related to the rotor status. An appropriate selection of the turn-on and turn-off angles (switching angles) is required for a high performance of the SRM [33]. This portion aims to define the optimal switching angles required for achieving the goals of maximum torque, maximum efficiency, and smallest torque ripple for the SRM. For optimal performance, both angles of switching should be preceded to energize the windings of the phase in the zone of low inductance to decay the current to zero, before the rotor passes the fully aligned position. The proposed is sophisticated for the 3-phase, 72/48 SRM, which has a 24-pole magnetic field per phase; the angle between aligned and unaligned positions is $3.75^{\circ}$. The switching angles can be utilized to dominance the copper loss, average of the torque, and torque ripple for a stable working of the SRM. A considerable number of approaches to optimize switching angles have been documented in earlier works [33-35]. The conduction angle is the difference between switching angles. The pole geometry of the prototype SRM has specific essential angles such as pole pitch, aligned rotor position, unaligned rotor position and stroke angle in Equation (6). The values of these angles for the prototype 72/48 SRM are presented in Table 5.

Table 5. Values of the essential angles for the prototype 72/48 SRM.

\begin{tabular}{cc}
\hline Angle [deg] & Values \\
\hline stroke angle & 2.5 \\
Stator pole pitch & 5 \\
Rotor pole pitch & 7.5 \\
Aligned rotor position & 7.5 \\
Unaligned rotor position & 3.75 \\
The electrical period & 7.5 \\
\hline
\end{tabular}

From the previous descriptions and calculations, the limitations of the switching angles are given as follows:

$$
\begin{gathered}
\theta_{u n} \leq \theta_{o n}<\tau_{s}, \\
\tau_{s} \leq \theta_{o f f}<\theta_{a n},
\end{gathered}
$$

where $\theta_{a n}, \theta_{u n}$ and $\tau_{s}$ are the aligned, unaligned angles, and the stator pole pitch, respectively.

According to the performance requirements of the $72 / 48$ SRM, we recommend the application of Equations (34) and (35) to obtain the optimum values of switching angles. The efficiency, torque and torque ripple for turn-on angles in the range of $2.5^{\circ}$ to $5^{\circ}$ turn-off angles in the range of $5^{\circ}$ to $7.5^{\circ}$ are presented in Figure 7. In addition, the optimum values of the turn-on angle $3.87^{\circ}$ and turn-off angle $6.37^{\circ}$ are shown in Figure 7. These optimal firing angles have confirmed the achievement of the required goals. The values of efficiency, torque and torque ripple at the optimal firing angles are provided in Table 6. The calculation of the optimal value of the $\theta_{o n}$ and $\theta_{o f f}$ after the $\theta_{u n}$ and before the $\theta_{a n}$, respectively. Moreover, the sequence of the optimal $\theta_{o n}, \theta_{o f f}, \theta_{u n}$ and $\theta_{a n}$ for the three phase $72 / 48$ SRM is listed in Table 7.

Table 6. The 72/48 SRM performance at optimal firing angles.

\begin{tabular}{cc}
\hline Parameters & Values \\
\hline Efficiency [\%] & 90.25 \\
Torque $[\mathrm{kN} \cdot \mathrm{m}]$ & 7.288 \\
Torque ripple [\%] & 30.7 \\
\hline
\end{tabular}


Table 7. The optimal $\theta_{o n}, \theta_{\text {off }}, \theta_{u n}$ and $\theta_{a n}$ of three phase $72 / 48$ SRM.

\begin{tabular}{ccccc}
\hline Phase & $\boldsymbol{\theta}_{\boldsymbol{u} \boldsymbol{n}}[\mathbf{d e g}]$ & $\boldsymbol{\theta}_{\boldsymbol{a n}}[\mathbf{d e g}]$ & $\boldsymbol{\theta}_{\boldsymbol{o n}}[\mathbf{d e g}]$ & $\boldsymbol{\theta}_{\boldsymbol{o f f}}[\mathbf{d e g}]$ \\
\hline Phase A & 3.75 & 7.5 & 3.87 & 6.37 \\
Phase B & 6.25 & 10 & 6.37 & 8.87 \\
Phase C & 8.75 & 12.5 & 8.87 & 11.37 \\
\hline
\end{tabular}

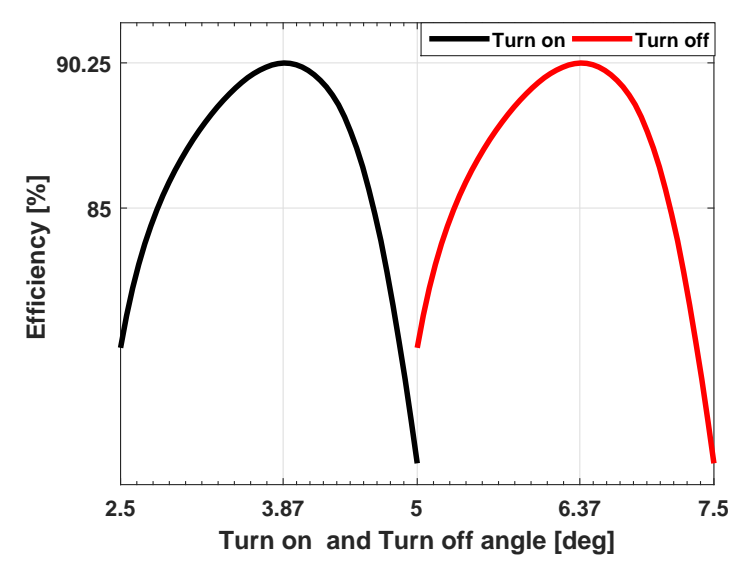

(a)

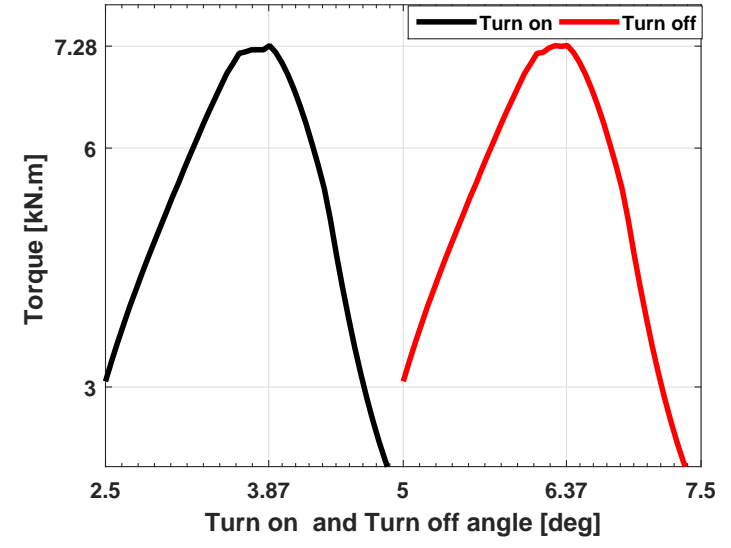

(b)

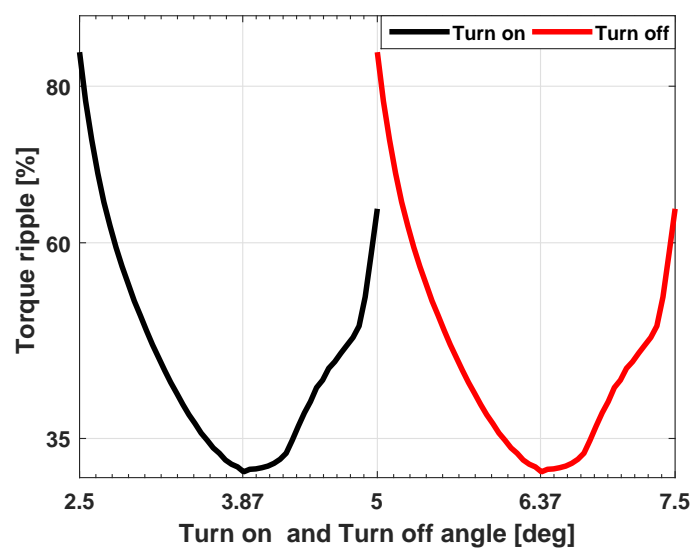

(c)

Figure 7. The performance of the 72/48 SRM versus firing angles. (a) efficiency; (b) torque; (c) torque ripple.

\section{Static Characteristics of the SRM}

The static characteristics of the SRM are discussed in detail. The calculation of the static torque curve is a useful application [36]. The phase winding is excited near the unaligned position to reach a desirable current quickly and cut off before the aligned position to avoid a negative torque. The angle of $3.75^{\circ}$ refers to the fully unaligned position and the angle of $7.5^{\circ}$ represents the fully aligned position. Torque versus currents from $50 \mathrm{~A}$ to $212 \mathrm{~A}$ and positions, determined by the finite element analysis (FEA), are illustrated in Figure 8 . The torque file proves that position range from $4.8^{\circ}$ to $7^{\circ}$ generates the peak torque. The torque approaches near zero both around aligned and unaligned position. 


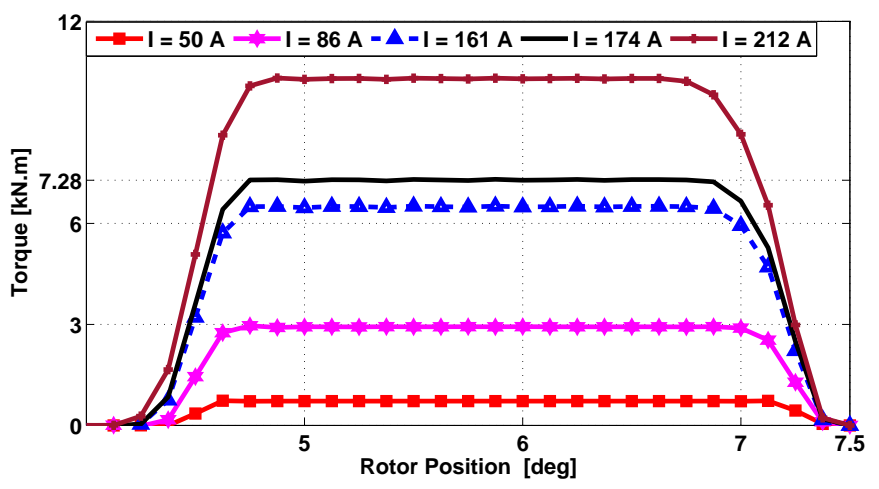

Figure 8. Torque curves of a $72 / 48$ SRM versus rotor position for range currents.

A 2D finite element models for the proposal machine is developed to obtain its electromagnetic characteristics. The flux density distribution in the machine at rated speed $105 \mathrm{rpm}$ and rated load $7.28 \mathrm{kN} \cdot \mathrm{m}$ can be seen in Figure 9. The machine flux density of the stator slot reaches the highest amount when the phase winding energized. Saturation will show up as the flux density rises to $1.7 \mathrm{~T}$, for the material used overall in normal conditions without causing overheating issues.

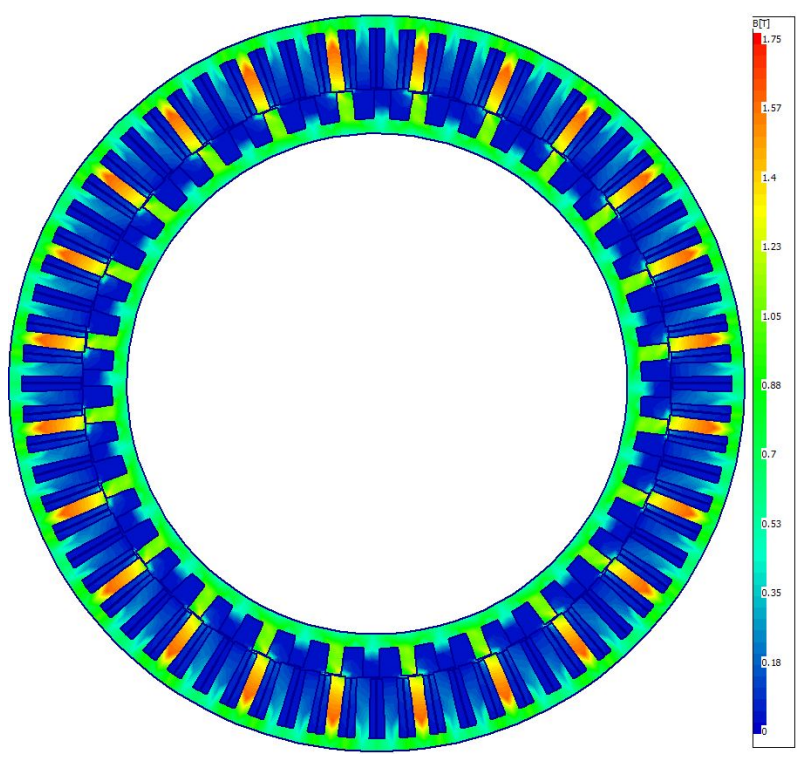

Figure 9. The distributions of the flux density of a 72/48 SRM as obtained from the 2D finite element models.

\section{Simulation Results}

The displaying technique for the switched reluctance drive (SRD) system is based on ANSYS MAXWELL and SIMPLORER (version 17). A 75-kW three-phase 72/48 SRM was designed as a prototype. The performance of the motor is obtained using ANSYS MAXWELL, and the asymmetrical half-bridge power converter circuit and control circuit, which is modelled in SIMPLORER as shown in Figure 10. The converter contains six insulated gate bipolar transistors (IGBTs). The stator windings are connected between upper and lower switches. Six diodes are necessary to provide a return path for return current. The power converter is fed from a $510 \mathrm{~V}$ DC source. The drive is controlled by current hysteresis and voltage pulse width modulation (PWM) methods. Information about the position of the rotor is a key issue to control the system. A good torque control scheme requires the knowledge of rotor inductance profile. The hysteresis control is like a simple and fast response with the switching frequency of $350 \mathrm{kHz}$. 


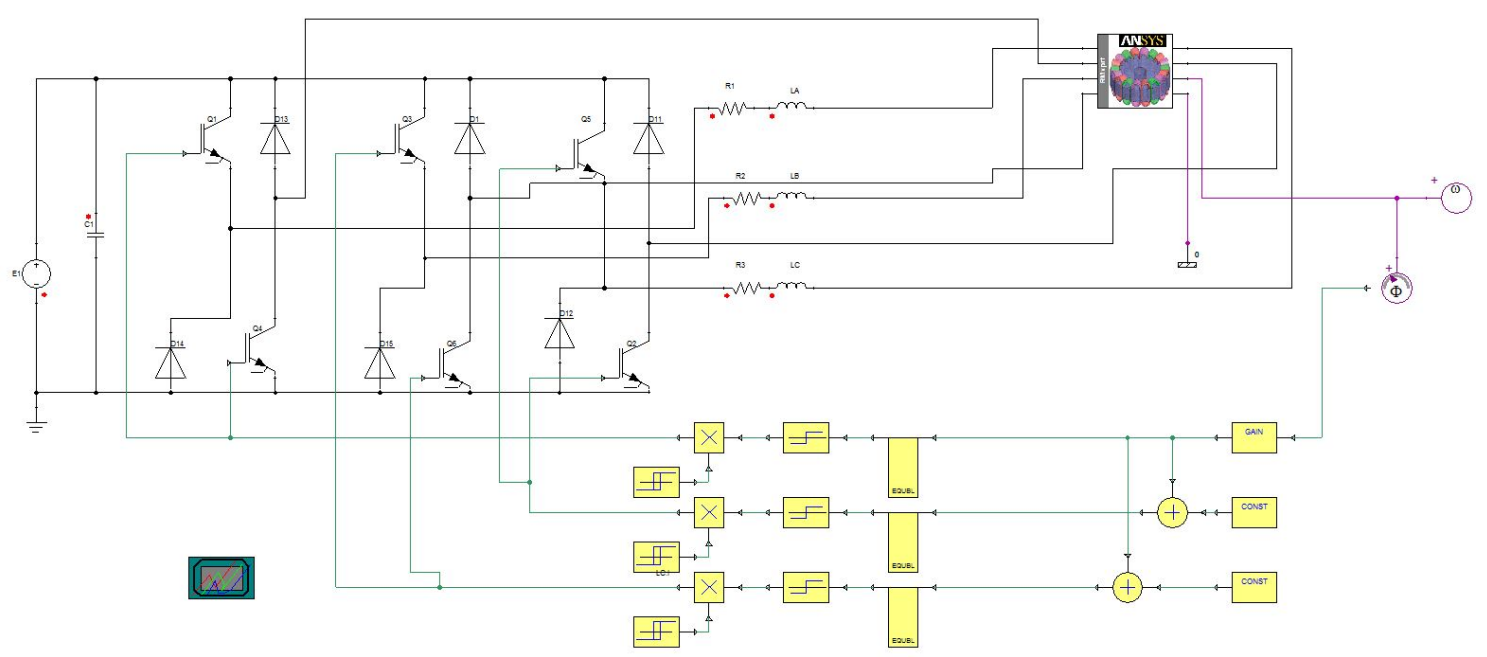

Figure 10. Switched reluctance drive system.

All the techniques of the SRM were formulated on the monitoring insulated gate bipolar transistor (IGBT) that implements the trigger logic depending on the different phases. If the single-phase winding of the motor is turned on, the windings of each phase are repeatedly turned on once every $7.5^{\circ}$. At the beginning, current chopper control of the phase $\mathrm{A}$ is implemented with a turn-on angle of $3.87^{\circ}$ and a turn-off angle of $6.37^{\circ}$, the sequence of phase B and C is described in Table 7 . The designed 72/48 SRM was implemented, and the instantaneous values of the current and electromagnetic torque were determined at the operating point. The electromagnetic torque and phase currents were specified as functions of the rotor position, as shown in Figures 11 and 12. Averages of the torque and DC current were obtained as $7.28 \mathrm{kN} \cdot \mathrm{m}$ and $174 \mathrm{~A}$, respectively.

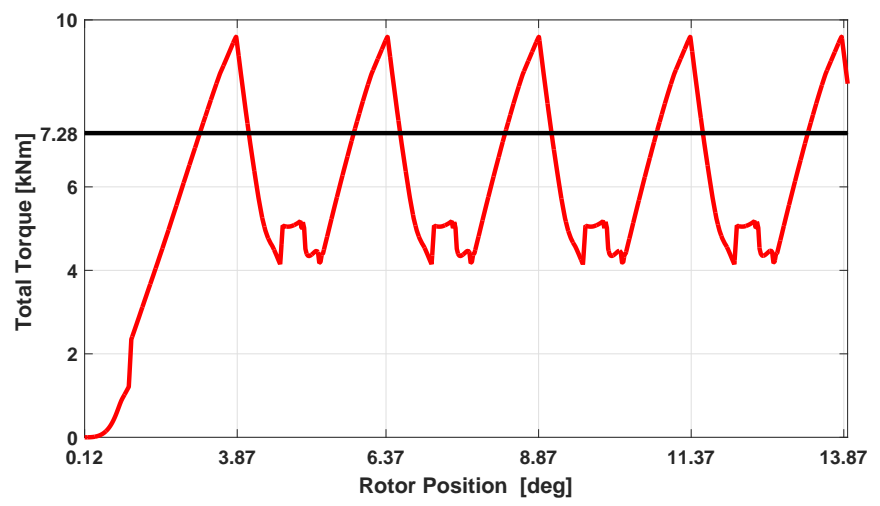

Figure 11. Torque versus rotor position.

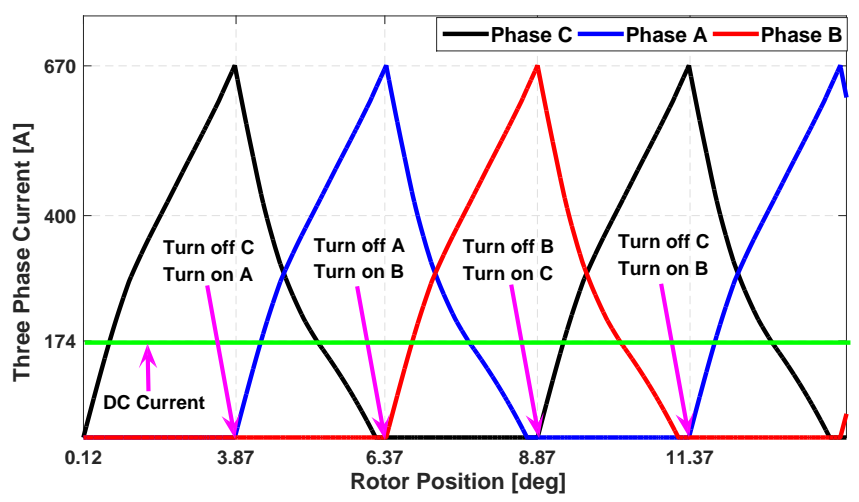

Figure 12. Current versus rotor position. 
The applied domain of the switching angles is governed by the inductance outline. The inductance of a stator phase is minimal in the unaligned status and maximal in the aligned status, as shown in Figure 13.

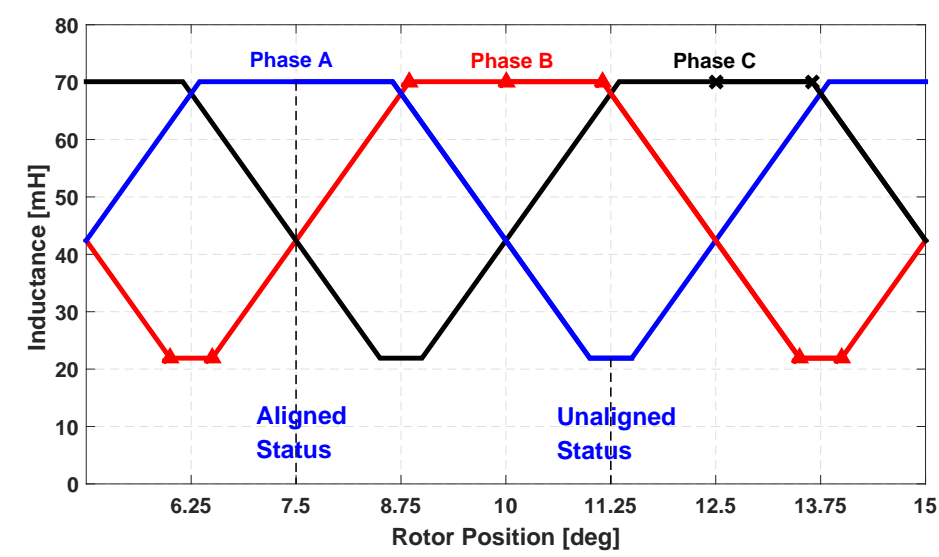

Figure 13. Inductance versus rotor position.

\section{Experimental Setup and Its Verification}

The aim of this experiment is to validate the suggested method. To confirm the developed design and computation methods, 72/48 SRM was designed and a prototype was manufactured, as shown in Figure 14. The design specifications, which are characterized by the proposed method, are summarized in Table 4.

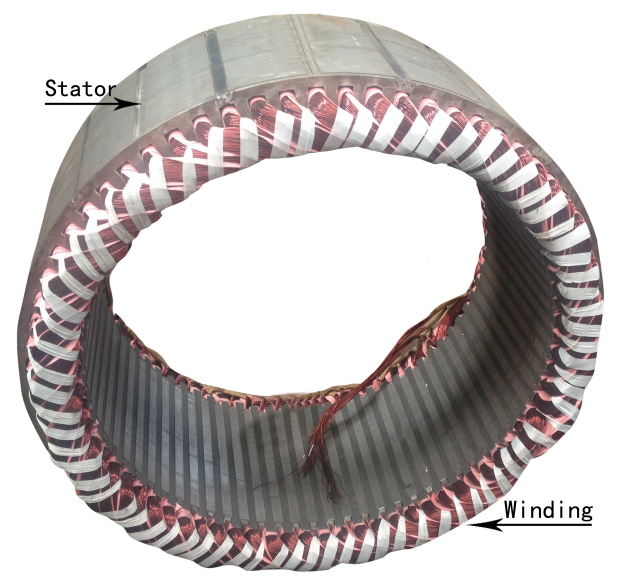

(a)

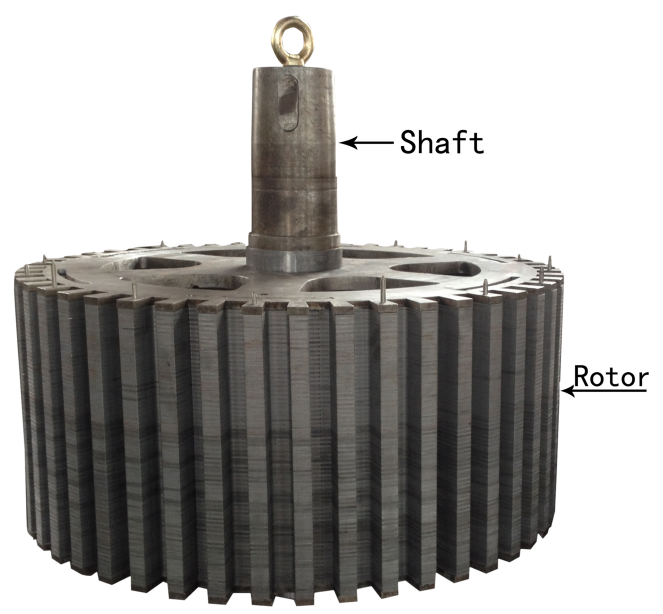

(b)

Figure 14. Construction of prototype 72/48 SRM fabrication. (a) the stator and winding fabrication; (b) the rotor and shaft fabrication.

The measurement results were compared with the steady-state analytical and simulation results to verify the previous calculations. It should be noted that the 72/48 SRM was designed for a rated speed of $105 \mathrm{rpm}$. Furthermore, the continuous output phase (DC) current rating of the power converter was $174 \mathrm{~A}$, and a DC bus voltage of $510 \mathrm{~V}$ was used to energize the 72/48 SRM. The experimental platform for $72 / 48$ SRM is developed and shown in Figure 15. 


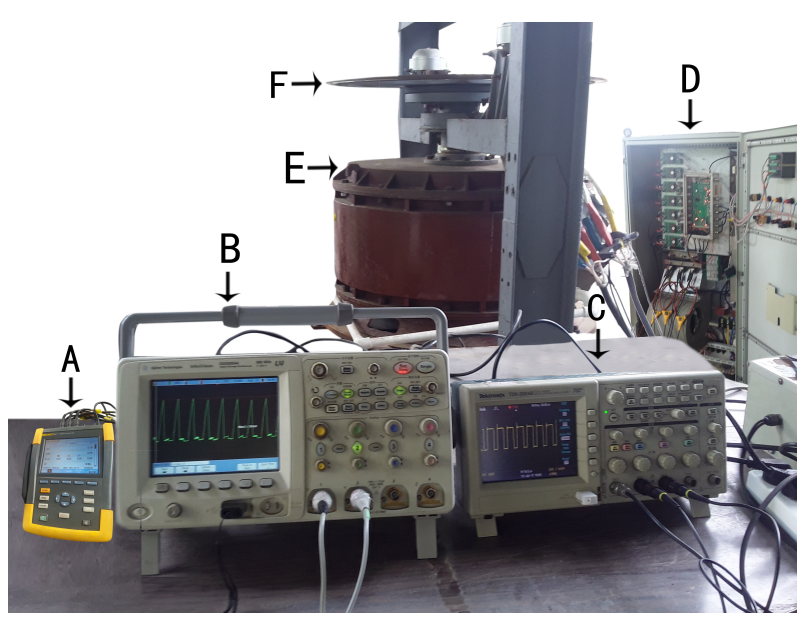

Figure 15. The experimental platform for the 72/48 SRM system.

The experimental platform of Figure 15 consists of:

(A) Three-Phase Power Quality Analyzer Fluke 434,

(B) Digital Oscilloscope (Measured Current),

(C) Digital Oscilloscope (Measured Voltage),

(D) Power Supply and Control System,

(E) 72/48 Prototype SRM,

(F) The Load Disc is Connected Directly to SRM.

To carry out these experiments, several types of equipment such as a three-phase power quality analyzer (Fluke 434) and an oscilloscope using a Hall sensor are utilized to record the input and output. The speed is measured using an optical digital tachometer (DT2235A, Shenzhen Sanpo Instrument Co., Ltd, Shenzhen, Guangdong Province, China). The resulting pulse-width modulation waveforms from the experiment are shown in Figure 16. Resulting three-phase current waveforms for the no-load and load tests are shown in Figure 17. There is an excellent symmetry between the three phases, as the current waveform shapes are similar to each other. This illustrates that there is a good agreement between the experimental results and the simulation results as shown in Figure 12. Therefore, the simulation provides sufficient confidence to predict the performance of the proposed SRM. Table 8 lists the experimental results at different loading conditions. A three-phase power analyser Fluke 434 is utilized for measuring the total harmonic distortion (THD) and K factor of the supply current as shown in Figure 18.

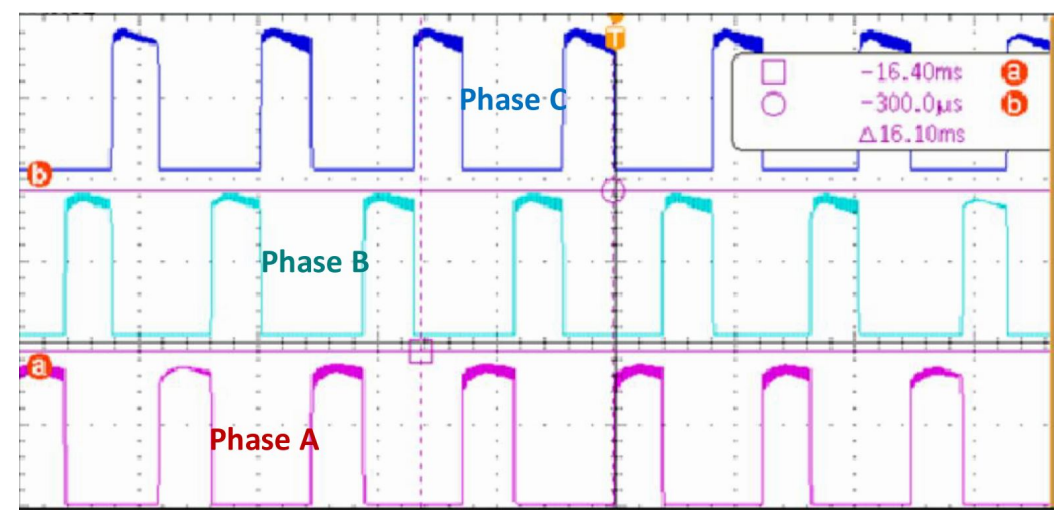

Figure 16. Pulse width modulation waveform. 


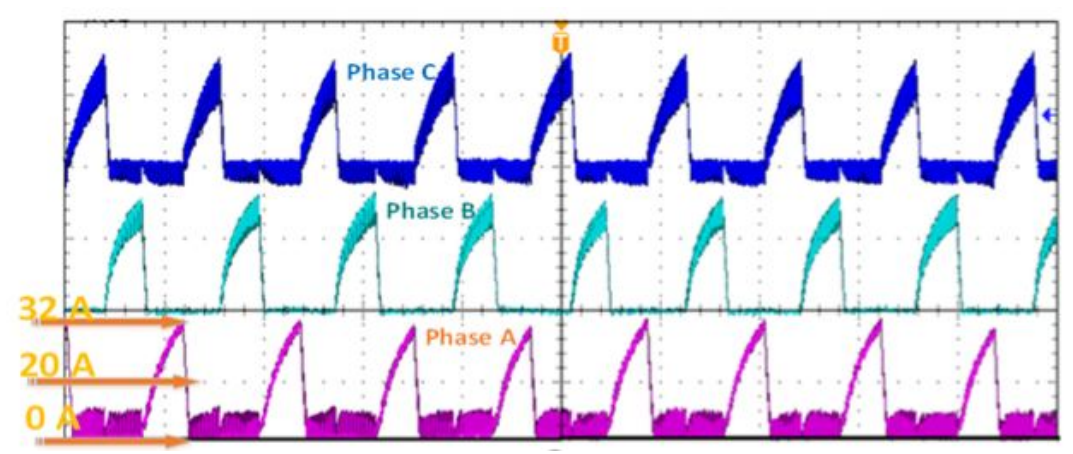

(a)

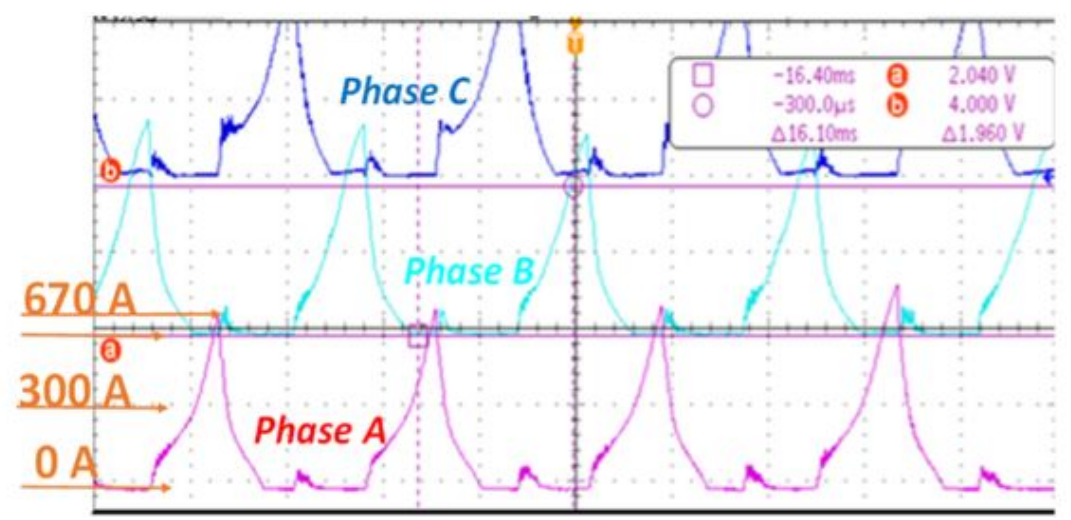

(b)

Figure 17. Current waveform of prototype 72/48 SRM (a) no load; (b) load.

Table 8. Experimental results for loading tests.

\begin{tabular}{lccccccc}
\hline Parameters & Test (1) & Test (2) & Test (3) & Test (4) & Test (5) & Test (6) & Test (7) \\
\hline Speed [rpm] & 105 & & & & & & \\
DC Voltage [V] & 510 & & & & & & \\
DC Current [A] & 5.01 & 11.15 & 12.88 & 57.1 & 85.7 & 114.3 & 171.5 \\
Total Loss [kW] & 2.5 & 2.8 & 2.94 & 3.95 & 4.813 & 5.95 & 8.59 \\
Torque [kN·m] & 0.005 & 0.262 & 0.330 & 2.32 & 3.56 & 4.78 & 7.20 \\
Efficiency [\%] & 2.3 & 50.7 & 55.2 & 86.4 & 88.9 & 89.7 & 90.19 \\
\hline
\end{tabular}

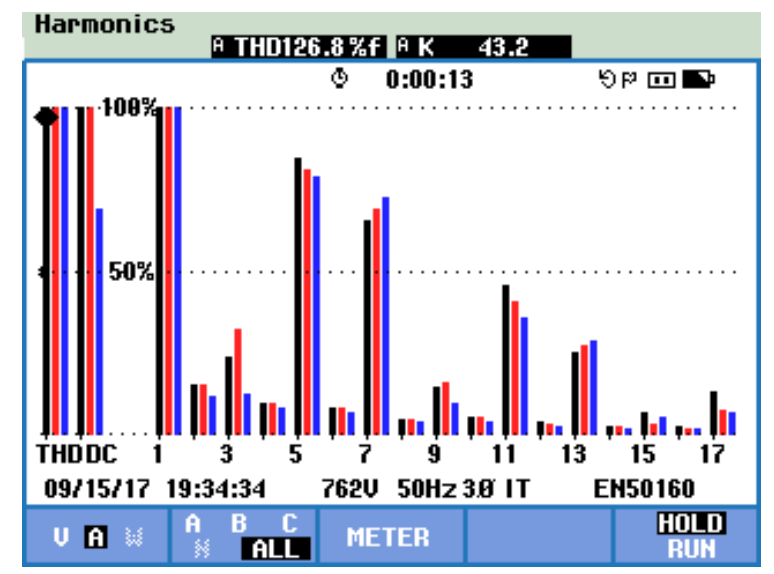

Figure 18. The total harmonics distortion and $K$ factor of the supply current for 72/48 SRM. 
Table 9 includes a comparison between the experimental results of proposed SRM, catalog data onto induction motor 2SIE 280 S4 and gear drive system. It can be seen that the proposed design gives a higher torque and better performance for mining applications.

Table 9. Performance/cost comparison of 72/48 SRM and induction motor 2SIE 280 S4 in the Raymond Pulverizing application.

\begin{tabular}{lccc}
\hline Parameters & 72/48 SRM & IM (2SIE 280 S4) & Gear Drive System \\
\hline Power [kW] & 75 & 75 & 75 \\
Rate speed [rpm] & 105 & 1488 & 105 \\
Torque [kN·m] & 7.28 & 0.481 & 7 \\
Efficiency at full load [\%] & 90.19 & 94.2 & 59.32 \\
Weight [kg] & 1180 & 678 & 1050 \\
Price of motor [USD] & 12,000 & 9000 & 1350 \\
\hline
\end{tabular}

\section{Conclusions}

This paper has presented a high-performance 72/48 SRM for mining application. The machine design and optimization help to develop the motor geometry in order to improve the average torque and minimize torque ripple. The developed machine is experimentally tested to verify machine models and simulation results. The proposed machine could increase the torque up to $7.28 \mathrm{kN} \cdot \mathrm{m}$ with a high efficiency of $90.19 \%$, whereas the geared drive system provides only an efficiency of $59.32 \%$ under similar operating conditions. Experimental and simulation results have confirmed that the SRM can be used as a substitute for the induction motor drive in mining (Raymond Pulveriser) applications. The proposed work exhibits a promising agreement with simulation as well as experimental results.

Acknowledgments: This work was supported in part by the International Science and Technology Co-operation Program of China under (Grant No. 2014DFR50880).

Author Contributions: Esmail Elhomdy and Jiang Liu conducted the literature review and tested the 72/48 switched reluctance motor. Guofeng Li and Esmail Elhomdy developed the idea and optimization methods. Wen-Ping Cao and Esmail Elhomdy provided the machine design principles and wrote the paper. Esmail Elhomdy and Syed abid Bukhari generated finite element method models and carried out simulation work .

Conflicts of Interest: The authors declare no conflict of interest.

\section{References}

1. Suzuki, M. Direct Drive Technology and Its Impact on Gearmotor Business. Available online: http:/ / www.powertransmission.com (accessed on 8 September 2017).

2. Raymond Mills. Available online: http://www.arvos-group.com (accessed on 1 September 2017).

3. Three-PhaseInduction Motors-2SIE280S4. Available online: http:/ /www.cantonigroup.com (accessed on 3 September 2017).

4. Mahdavian, H. A smart motor drive system for domestic and industrial applications. Ph.D. Thesis, Victoria University of Technology, Victoria, Australia, 2001.

5. Hashemnia, N.; Asaei, B. Comparative study of using different electric motors in the electric vehicles. In Proceedings of the 2008 18th International Conference on Electrical Machines, Vilamoura, Portugal, 6-9 September 2008; pp. 1-5, doi:10.1109/ICELMACH.2008.4800157.

6. Yildirim, M.; Polat, M.; Kürüm, H. A survey on comparison of electric motor types and drives used for electric vehicles. In Proceedings of the 2014 16th International Power Electronics and Motion Control Conference and Exposition, Antalya, Turkey, 21-24 September 2014; pp. 218-223, doi:10.1109/EPEPEMC.2014.6980715.

7. Jung, J.; Ulbrich, S.; Hofmann, W. Design process of a high torque density direct drive involving a transverse flux machine. In Proceedings of the 2014 International Conference on Electrical Machines (ICEM), Berlin, Germany, 2-5 September 2014; pp. 1096-1102, doi:10.1109/ICELMACH.2014.6960318.

8. Ilic, M.; Marino, R.; Peresada, S.; Taylor, D. Feedback linearizing control of switched reluctance motors. IEEE Trans. Autom. Control 1987, 32, 371-379, doi:10.1109/TAC.1987.1104616. 
9. Wallace, R.S.; Taylor, D.G. Low-torque-ripple switched reluctance motors for direct-drive robotics. IEEE Trans. Robot. Autom. 1991, 7, 733-742, doi:10.1109/70.105382.

10. Ray, A. Design and Performance Evaluation of Switched Reluctance Machines with Higher Number of Rotor Poles for Low Power Propulsion Applications. Ph.D. Thesis, Illinois Institute of Technology, Chicago, IL, USA, 2013.

11. Raj, M.A.; Kavitha, A. Effect of Rotor Geometry on Peak and Average Torque of External Rotor Synchronous Reluctance Motor (Ex-R SynRM) in comparison with Switched Reluctance Motor for Low Speed Direct Drive Domestic Application. IEEE Trans. Ind. Appl. 2015, 53, doi:10.1109/TMAG.2017.2710191.

12. Chen, H.; Zhang, D. The Switched Reluctance Motor Drive for the Direct-Drive Joint of the Robot. IEEE Trans. Ind. Appl. 2001, 2, doi:10.1109/ROBOT.2001.932812.

13. Krishnan, R. Switched Reluctance Motor Drives: Modeling, Simulation, Analysis, Design, and Applications; CRC Press: Boca Raton, FL, USA, 2001; ISBN: 0849308380.

14. Harris, M.; Miller, T.E. Comparison of design and performance parameters in switched reluctance and induction motors. In Proceedings of the 1989 Fourth International Conference on Electrical Machines and Drives, London, UK, 13-15 September 1989; pp. 303-307.

15. Shoujun, S.; Weiguo, L.; Peitsch, D.; Schaefer, U. Detailed design of a high speed switched reluctance starter/generator for more/all electric aircraft. Chin. J. Aeronaut. 2010, 23, 216-226.

16. Jeong, G.I.; Xu, Z.; Ahn, J.W. Design of SRM considering dual drive modes. In Proceedings of the 2014 IEEE International Conference on Industrial Technology (ICIT), Busan, Korea, 26 February-1 March 2014; pp. 872-876, doi:10.1109/ICIT.2014.6895014.

17. Krishnan, R.; Arumugan, R.; Lindsay, J.F. Design procedure for switched-reluctance motors. IEEE Trans. Ind. Appl. 1988, 24, 456-461, doi:10.1109/28.2896.

18. Miller, T.J.E. Switched Reluctance Motors and Their Control; Magna Physics Pub.: Oxford, UK, 1993; ISBN: 1881855023.

19. Miller, T.J.E. Brushless Permanent-Magnet and Reluctance Motor Drives; Oxford University Press: Oxford, UK, 1989; ISBN: 0198593694.

20. Miller, T.J.E. Electronic Control of Switched Reluctance Machines; Newnes: Oxford, UK, 2001; ISBN: 9780750650731.

21. Miller, T.J.E. Optimal design of switched reluctance motors. IEEE Trans. Ind. Electron. 2002, 49, 15-27, doi:10.1109/41.982244.

22. De Doncker, R.; Pulle, D.W.; Veltman, A. Advanced Electrical Drives: Analysis, Modeling, Control; Springer Science \& Business Media: Berlin, Germany, 2010; ISBN: 9400701799.

23. Nakano, S.; Kiyota, K.; Chiba, A. Design consideration of high torque-density switched reluctance motor for hybrid electrical vehicle. In Proceedings of the 2016 19th International Conference on Electrical Machines and Systems (ICEMS), Chiba, Japan, 13-16 November 2016; pp. 1-6.

24. Hayashi, H.; Nakamura, K.; Chiba, A.; Fukao, T.; Tungpimolrut, K.; Dorrell, D.G. Efficiency improvements of switched reluctance motors with high-quality iron steel and enhanced conductor slot fill. IEEE Trans. Energy Convers. 2009, 24, 819-825, doi:10.1109/TEC.2009.2025425.

25. Wichert, T. Design and construction modifications of switched reluctance machines. Ph.D. Thesis, Warsaw University of Technology, Warszawa, Poland, 2008.

26. Chen, Y.; Pillay, P. An improved formula for lamination core loss calculations in machines operating with high frequency and high flux density excitation. In Proceedings of the 37th IAS Annual Meeting, Pittsburgh, PA, USA, 13-18 October 2002; Volume 2, pp. 759-766, doi:10.1109/IAS.2002.1042645.

27. Kampen, D.; Owzareck, M.; Beyer, S.; Parspour, N.; Schmitt, S. Analytical core loss models for electrical steel in power electronic applications. In Proceedings of the 2012 13th International Conference on Optimization of Electrical and Electronic Equipment (OPTIM), Brasov, Romania, 24-26 May 2012; pp. 109-117, doi:10.1109/OPTIM.2012.6231805.

28. Pyrhonen, J.; Jokinen, T.; Hrabovcova, V. Design of Rotating Electrical Machines; John Wiley \& Sons: New York, NY, USA, 2013; ISBN: 978-1-118-58157-5.

29. Gieras, J.F. Permanent Magnet Motor Technology: Design and Applications; CRC Press: Boca Raton, FL, USA, 2002; ISBN: 1420064401.

30. Krings, A. Iron Losses in Electrical Machines-Influence of Material Properties, Manufacturing Processes, and Inverter Operation. Ph.D. Thesis, KTH Royal Institute of Technology, Stockholm, Sweden, 2014. 
31. Mahmoud, S.M.; El-Sherif, M.Z.; Abdel-Aliem, E.S.; Nashed, M.N. Studying different types of power converters fed switched reluctance motor. Int. J. Electron. Electr. Eng. 2013, 1, 281-290.

32. Nie, Z.; Schofield, N. Analysis and comparison of power electronic converters for conventional and toroidal switched reluctance machines. In Proceedings of the 8th IET International Conference on Power Electronics, Machines and Drives (PEMD 2016), Glasgow, UK, 19-21 April 2016; pp. 1-6, doi:10.1049/cp.2016.0229.

33. Zan, X.; Huo, Y.; Gu, J. Optimization research of turn-on angle and turn-off angle based on switched reluctance starter/generator system. In Proceedings of the 2015 IEEE 28th Canadian Conference on Electrical and Computer Engineering (CCECE), Halifax, NS, Canada, 3-6 May 2015; pp. 864-869, doi:10.1109/CCECE.2015.7129388.

34. Borujeni, M.M.; Rashidi, A.; Nejad, S.M.S. Optimal four quadrant speed control of switched reluctance motor with torque ripple reduction based on EM-MOPSO. In Proceedings of the The 6th Power Electronics, Drive Systems \& Technologies Conference (PEDSTC2015), Tehran, Iran, 3-4 February 2015; pp. 310-315, doi:10.1109/PEDSTC.2015.7093293.

35. Jiang, J.W.; Bilgin, B.; Howey, B.; Emadi, A. Design optimization of switched reluctance machine using genetic algorithm. In Proceedings of the 2015 IEEE International Electric Machines \& Drives Conference (IEMDC), Coeur d'Alene, ID, USA, 10-13 May 2015; pp. 1671-1677, doi:10.1109/IEMDC.2015.7409288.

36. Radun, A.V. Design considerations for the switched reluctance motor. IEEE Trans. Ind. Appl. 1995, 31, 1079-1087, doi:10.1109/IAS.1994.377482.

(C) 2018 by the authors. Licensee MDPI, Basel, Switzerland. This article is an open access article distributed under the terms and conditions of the Creative Commons Attribution (CC BY) license (http:/ / creativecommons.org/licenses/by/4.0/). 